\title{
SUPPORTING SUSTAINABLE TRANSPORT APPRAISALS USING STAKEHOLDER INVOLVEMENT AND MCDA
}

\author{
Michael Bruhn BARFOD* \\ Dept of Management Engineering, Technical University of Denmark, Kongens Lyngby, Denmark
}

Received 30 August 2016; revised 19 May 2017, 2 August 2017; accepted 24 November 2017

\begin{abstract}
Appraisal processes for transport initiatives are often characterised by their complexity involving a wide range of impacts that need to be addressed and many stakeholders that attempt to influence the decisions to be made. The increasing interest for the environment and sustainable development in general has stressed the need for taking a broad perspective into account when addressing transport initiatives. This means that economic, social and environmental dimensions need to be considered simultaneously in the appraisal process. The focus on incorporating such sustainability considerations has set new demands for the appraisal process and has revealed an increasing need for involving stakeholders in the decision support process to capture all aspects of the often complex decision problems. Conventional appraisals within the transport area are often only based on cost-benefit analysis, which captures the impacts that can be assigned with a monetary value. Thus there is a need for a decision support system that is able to assess the effect of other types of impacts as well and include this in the appraisal. This paper seeks to fill this gap in research by proposing a methodology making use of planning workshops and multi-criteria decision analysis in combination to improve the decision support. In order to serve the purpose of promoting a more sustainable transport planning approach a proposal is made for how the methodology can be integrated in the current practice for appraisal of infrastructure projects in Denmark (and countries with similar approaches). The paper concludes that the approach allowing for active stakeholder participation in the appraisal process can serve as a helpful and effective decision support system in the quest for more sustainable solutions to transport problems.
\end{abstract}

Keywords: sustainable transport appraisal, stakeholder involvement, multi-criteria decision analysis, cost-benefit analysis, decision support systems, appraisal processes.

\section{Introduction}

Frameworks for appraising transport infrastructure projects differ from country to country; however, a conventional Cost-Benefit Analysis (CBA) is to some extent conducted in most countries (Beukers et al. 2012; Vickerman 2000; Hayashi, Morisugi 2000). Hereby CBA provides the decision-makers with a monetary assessment of the profitability of the project alternatives. However, the decisionmakers will often experience difficulties in finding the right balance between the expert knowledge produced by the CBA and the knowledge produced by the participation of various stakeholders in the decision making process (Damart, Roy 2009). This paper seeks to fill this gap in research by proposing a methodology making use of planning workshops and Multi-Criteria Decision Analysis (MCDA) in combination to improve decision support.

Often an Environmental Impact Assessment (EIA) is performed taking into account the impacts that for various reasons cannot be included in the CBA. Performing an EIA is a fundamental requirement for all major infrastructure projects in Denmark, and the first law on EIA and appraisal of public (and some private) projects were initiated back in June 1985 (DMT 2015). In the final decision making the EIA is used as a complementing document to the socio-economic appraisal, but in practice it is unclear how much the two types of appraisal contribute to the decision made. This paper deals with this situation.

Even though various stakeholders take part in the debate concerning infrastructure projects, and try to affect the final decision they are not formally included in the appraisal process outlined above. Thus a need has arisen for a revision of the decision support process, which can take all aspects of the decision problem into account and at the same time include relevant stakeholders. A new Decision Support System (DSS) is for this reason suggested for the decision process. The DSS can be customised to each specific assessment task using techniques that reflect

${ }^{*}$ Corresponding author. E-mail: mbba@dtu.dk 
the current needs and the composition of the decisionmakers and/or stakeholders participating. This means that the DSS is constructed through an interactive and consultative process between owners of the problem and specialists (Phillips 1984). The stakeholder interaction with the DSS is proposed to take place using the planning workshop concept such as described by Phillips and Bane e Costa (2007) and Phillips (2007), where key players are brought together under the guidance of a facilitator with the purpose of discussing and assessing relevant issues.

The proposed DSS is designed to bring informed decision support by allowing for the decision making process to be expanded beyond the consideration of the conventional economic factors. The DSS makes use of a set of techniques that are customised to the specific decision task at hand (Barfod, Salling 2015). Hence, no specific MCDA technique is linked to the DSS and it is possible to use different techniques as well as combinations of them depending on the relevance for the decision problem in hand.

The current practice in the Danish planning process is that the choice whether the problem is to be solved by constructing new infrastructure or for instance by public transport is taken already at the early stage. However, in this paper it is proposed that this choice is postponed to the final stage of the process, and that the different types of solutions 'compete' against each other until this stage. In this way it is ensured that all types of solutions undergo the same thorough analysis, and the likelihood that the most sustainable alternative is selected is increased.

Hence, the aim of this paper is to provide a proposal for a structured decision support process, which is capable of including stakeholders and at the same time base the appraisal on a wider set of decision criteria compared to the conventional Danish practice. Thus, the paper show that increased stakeholder participation in decision support processes concerning transport initiatives can improve the decision support and at the same time contribute to a more sustainable development in transport planning. The motivation of this study is to develop a methodology and process guidelines, which can assist in moving the Danish (and countries with similar approaches) appraisal process from conventional impact assessment considering only a narrow set of project alternatives to a more comprehensive type of assessment that also considers other - and perhaps more sustainable - options for solving the transport issue at hand. Thereby the study has the potential of contributing to a more sustainable transport planning approach on the national level.

The paper is composed as follows. After this introduction, Section 1 provides an overview of the literature within the area and outlines the definitions used in the paper. Subsequently, section 2 introduces the methodological approach of the paper with focus on the three main phases of the decision support process. The use of MCDA and stakeholder participation within transport planning is outlined, and the concept of planning workshops is pro- posed featuring a five-step process that leads the participants through the appraisal process. Section 3 provides a proposal for where the methodology can be implemented in the current Danish appraisal process for transport initiatives. Section 4 presents a case study used to illustrate the steps within the three main phases of the methodology and the technical part of the DSS. Finally, Section 5 discusses the methodology, and a conclusion is made.

\section{Literature and definitions}

It is widely acknowledged that the decision making regarding infrastructure projects (and many other types of decision problems) often are influenced by other types of impacts besides the monetarily assessed, which may have the possibility of improving the decision support (Leleur 2012; Noland 2007). In order to assess these impacts, which often cannot be monetised, the concept of MCDA is introduced. MCDA has previously been applied for decision support for various issues dealing with environment and sustainability within the transport area (Mardani et al. 2016; Camargo Pérez et al. 2015; Barfod 2012a, 2012b; Sayers et al. 2003). E.g. Hsu et al. (2015) develops a cloudbased service framework for reducing $\mathrm{CO}_{2}$ emissions in Intelligent Transport Systems (ITS), López et al. (2012) assess energy efficiency and sustainability scenarios in the transport system using an MCDA approach, Awasthi and Chauhan (2011) makes use of the Analytic Hierarchy Process (AHP) to evaluate sustainable transport solutions, Pai et al. (2007) makes use of a grey systems theory to evaluate transport effects on air quality, Tzeng et al. (2005) apply AHP, the Technique for Order of Preference by Similarity to Ideal Solution (TOPSIS) and multi-criteria optimization and compromise solution (VIKOR, in Serbian: VIseKriterijumska Optimizacija I Kompromisno Resenje) technique to assess alternative-fuel busses for public transportation in Taiwan, Fedra (2004) develops an indicator framework and multi-criteria models to evaluate sustainable urban transportation scenarios, Yedla and Shrestha (2003) makes use of MCDA for assessing alternative options for environmentally sustainable transport systems in India, and Ewing and Sarigöllü (2000) apply a MCDA approach to assess clean-fuel vehicles.

MCDA is based on value measurement using qualitative input from a ratifying group, and is a widely used methodology for assessing impacts that only with great difficulties can be quantified (Belton, Stewart 2002). In several countries (e.g. France, the Netherlands and the United Kingdom) MCDA has been widely applied for many years, and the methodology is fully accepted for decision support in the transport sector (Barfod 2012b; Leleur 2000). However, MCDA is not a fixed part of the appraisal scheme for infrastructure projects in all countries. In countries with long traditions for CBA (e.g. Sweden and Denmark) the methodology is not yet fully accepted as a valid decision aid due to its dependence on subjective qualitative input. Thus addressing this subjectivity and means to reduce it 
is therefore of utmost importance to a DSS making use of MCDA techniques to capture the sustainability dimension of transport projects.

Defining and measuring the sustainability of transport systems has - as evidenced by a growing number of initiatives around the world - been an area of great interest for policy and decision-makers throughout the last $2 \ldots 3$ decades. Jeon and Amekudzi (2005) attempt to characterise the thinking on what constitutes transport sustainability and how to define it by reviewing 16 sustainability initiatives around the world, and find that in order to be effective the assessment must include a strong stakeholder component.

Evidently, an increasing interest has throughout the recent decades emerged for stakeholder participation in decision support processes within the environmental and thereby the transport area (Reed 2008; Hansen, Mäenpää 2008; Abelson et al. 2007). This is not the least due to an increased interest for first of all the environment, but also for sustainable development in general meaning that economic, social and environmental dimensions need to be considered in combination in the decision support process. Despite the general acceptance of participation it can often be unclear what distinguishes public involvement from stakeholder participation. Many different definitions of participation exist - see e.g. OECD (2001); Steelman, Ascher (1997) - as it is used in various contexts and understood in several different ways (Davidson 1998; Reed 2008; Luyet et al. 2012). The definition will depend on the decision process and those who are to participate.

For the current paper participation is defined as: " $a$ process through which stakeholders influence and share control over development initiatives and the decision and resources, which affect them" (World Bank 1996). The purpose of stakeholder participation is then to enhance the quality of the project and the decisions made. In this respect project quality includes social learning and adequate technical solutions. This is possible to reach through the support and cooperation between the involved parties and the resulting input of knowledge (Phillips 2007; Belton, Stewart 2002).

The terms of public participation and stakeholder participation are used inconsistently in the literature. Often the public is considered as an unstructured and unorganised collection of individuals while stakeholders are defined as organised groups that share a common interest or stake in a particular issue or system (Luyet et al. 2012; Grimble, Wellard 1997). To simplify the terminology in this paper the public is considered as a stakeholder in itself, and for this reason the term stakeholder participation is used onwards.

Several applications have been dealing with the issue of stakeholder participation in the decision support process for transport initiatives (Franceschini, Marletto 2015). E.g. Jones et al. (2015) incorporates stakeholder input into transport project selection to increase prosperity in developing countries; Barfod and Salling (2015) makes use of a combination of MCDA techniques and stakeholder participation to assess the sustainability of different alternatives for a fixed link; Shiau, Liu (2013) and Shiau (2012) develops an indicator system for local governments to evaluate transport sustainability strategies in Taipei; Macharis et al. (2012) makes use of the MultiActor Multi-Criteria Analysis (MAMCA) to evaluate the sustainability of different transport initiatives; and Bana e Costa (2001) finds that MCDA using stakeholder involvement is a useful approach for the evaluation of transport policy options. Moreover, several studies indicate that spatial MCDA using e.g. GIS based solutions is very useful in participatory approaches for the assessment of the spatial components of criteria (Kropp, Lein 2012; Stich, Holland 2011; Keshkamat et al. 2009; Malczewski 1996, 2006). Thus, the literature reveals a strong link between sustainability assessments and stakeholder participation (Pryn et al. 2015; Karjalainen et al. 2013; Awasthi et al. 2011; Awasthi, Chauhan 2011; Salling, Pryn 2015), and highlights the need for allowing different stakeholder preferences to be tested during the decision support process (Pryn et al. 2015; Mohamadabadi et al. 2009; Shiftan et al. 2003; Salling, Pryn 2015).

This research in this paper seeks to bridge the gap between the conventional CBA based approach to transport project appraisal and the assessments of non-monetary impacts by using stakeholder involvement and MCDA. Previous studies has presented several successful applications of MCDA for transport planning in general and sustainability assessments in particular. Moreover, MCDA approaches using stakeholder participation for impact assessment have proven worthwhile. This paper combines the main findings from the above-mentioned studies in a novel approach, and enhances this previous research in making a proposal for implementing this approach in the current Danish appraisal scheme to support sustainable transport planning.

\section{Methodology}

Developing a methodological approach that uses wellknown techniques to meet the purpose of improving the transport appraisal process is the main objective of this paper. Hence, focus in the following will be on the application of the methodology in the main phases of the decision support process. The proposal for how MCDA and stakeholder participation ideally should be used in the decision support process is therefore outlined, and the concept of planning workshops is proposed featuring a process that leads the participants through the appraisal process.

In order to participate meaningfully in the process of decision making and to make well-informed decisions the decision-makers need information from decision support tools that help to assess the implications of project alternatives. The extent to which available data and tools can be used in group decision making dealing with these 
complex decisions, spanning the interrelated domains of economy, environment, and society, is examined. General speaking the decision support process can be divided into three main phases that are to be dealt with (Barfod 2012b; Belton, Stewart 2002; Von Winterfeldt, Edwards 1986). The phases are: the problem structuring phase (defining the problem, selecting an appropriate analytic approach, and developing a detailed analytic structure), the exploration phase (involving the stakeholders in the assessment of project alternatives), and the documentation phase, cf. Figure 1 . The phases will be treated separately below. Impartial decision analysts are used to structure and facilitate the process while making sure that all relevant aspects of the decision problem are covered.

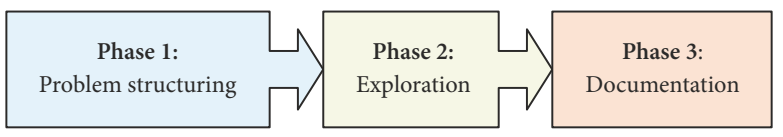

Figure 1. The three phases of the decision support process

\subsection{The problem structuring phase}

In the initial phase of a decision support process it is necessary to define the boundaries of the problem (Jeppesen 2009). It will be an advantage for the decision analysts, who are to structure and facilitate the decision support process, to conduct preliminary meetings with the stakeholders to ensure a wide understanding. This will enable the analysts to design the decision support process in terms of its content (what methods should be used and which materials are needed?), its duration (are time constraints an issue?), and the number and types of participants (how many relevant stakeholders should take part in the decision support process, and should they have expert knowledge about the problems?). However, before the above mentioned meetings can begin some issues need to be sorted out with regard to defining the problem, selecting an appropriate analytic approach, and developing a detailed analytic structure (Belton, Stewart 2002), cf. Figure 2 .

\subsubsection{Defining the problem}

In order to choose the right strategy of approaching the decision problem it is important to focus on the problem and define exactly what kind of problem that is to be solved. In this context it can be noted that a problem can have several sub-problems, which can be solved either one by one, or as a whole.

In the initial part of the structuring phase problems are often defined to wide, and thereby it can be difficult to identify solutions. There is also a risk of finding many new questions related to the problem instead of actually identifying possible solutions. Moreover, it can be difficult to identify the focus with complex planning problems as many things may interfere. In order to deal with such complex problems different soft methodologies can be applied. This could for example be creative methods for problem focusing and/or conceptual models based on the Soft Systems Methodology (SSM), which attempts to foster learning and appreciation of the problem in the stakeholder group rather than set out to solve a pre-defined problem (Checkland 1999).

Another important issue in the initial part of the problem structuring phase is to identify which alternative solutions there exist to the problem at hand. In most cases there will be several possible alternatives, each with different characteristics both with regard to economic costs and benefits as well as other types of consequences such as social and environmental impacts. The alternatives should be explained in detail in a way such that they can be understood by all stakeholders. This is in order to enable a comprehensive appraisal of the alternatives and provide the decision-makers with the best possible knowledge about the positive and negative aspects of all alternatives. For this part of the process the simple brainstorm technique can be of value to apply, e.g. based on information about the problem definition, preferences, boundaries and possibilities.

The next step in the initial part of the problem structuring phase involves an identification of possible and relevant stakeholders. The viewpoints of all stakehold-

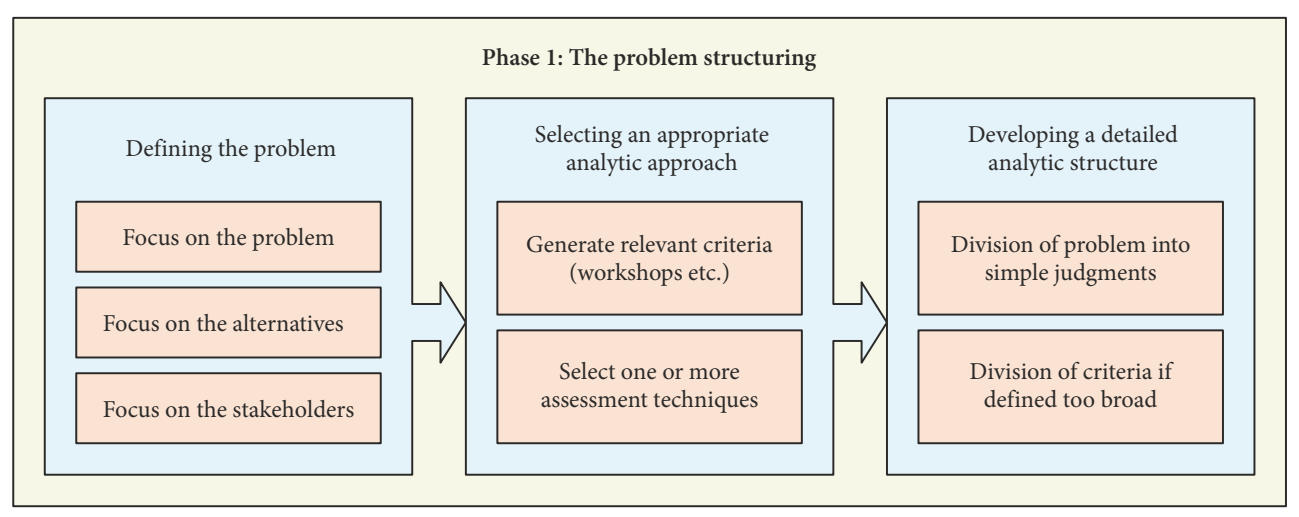

Figure 2. The problem structuring phase 
ers have to be defined in the initial problem structuring phase, and the level of influence of the stakeholders needs to be clarified as well. Stakeholder participation in the decision support process will help to ensure that different viewpoints can be taken into account at the final decision making. Hence it is decisive for the outcome of the process who are participating. A stakeholder analysis that identifies the involved and affected (both directly and indirectly) by the problem situation should be carried out in this phase. This contributes to the set-up of the remaining part of the decision support process where the stakeholders are to participate.

\subsubsection{Select an appropriate analytic approach}

Next the emphasis moves from problem structuring to model building (the DSS) where a specific analytic approach needs to be chosen. In this context the model building is regarded as a dynamic process, which both is informed by and informs the problem structuring process, and interacting with the process of appraisal. It may involve some iteration, search for new criteria, discarding, reinstating and redefining old ones, and further extensive discussions amongst the participants in the process (the stakeholders). Moving from a broad description of the problem, whether it is a simple clustering of ideas, a fully elaborated map, or some other representation of the issue, to a preliminary definition of a DSS, requires a good understanding of the chosen approach to multi-criteria modelling. The nature of the approach which is selected will differ according to the nature of the assessment task and whether the alternatives are explicitly or implicitly defined (Barfod, Salling 2015). The task of selecting an assessment technique might lead to the realisation that one single technique is not sufficient to meet the requirements of the decision problem. One technique might be useful for the scoring of alternatives while another technique is useful for the weighting of criteria; this depends on the problem to be assessed. Moreover, it can be a requirement that some impacts are assessed using a CBA, which is the case for most transport infrastructure projects.

\subsubsection{Develop a detailed analytic structure}

The input generated in Sections 2.1.1 and 2.1.2 leads to the development of a detailed analytic structure for the DSS. The chosen approach is used to structure the problem including all relevant criteria and alternatives creating sub-divisions if needed. The objective is to structure and decompose the problem into simple judgments for the participating group to consider.

\subsection{The exploration phase}

Once the problem structuring phase has been conducted it is possible to start the actual exploration and thereby appraisal of the problem. For this purpose the concept of planning workshops is proposed to bring stakeholders together with the purpose of obtaining common agreement on the problem situation. A planning workshop is a tool for organizing and structuring debate about complex problems involving several stakeholders. The main idea is to bring stakeholders into the decision support process and to enable a structured debate to enrich the basis on which decisions are to be made (Phillips, Bana e Costa 2007). The goal of the debate is not necessarily to obtain consensus in the group, but to accomplish acceptable and sustainable solutions for all participants as well as obtaining a common understanding and a group commitment.

Thus a planning workshop consists of three main elements: group processes, information technology, and decision analysis. Decision support techniques are introduced as on-the-spot modelling and used in the workshop with an emphasis on the participants understanding every step, so no black-box process/solutions will occur (Phillips, Bane e Costa 2007). The decision analysis techniques are explained along the workshop, and based on these the constructed DSS is used throughout the process. Phillips and Bane e Costa (2007) point out that the focus of the workshop should be on the social group processes rather than on the technical part of the DSS. The set-up furthermore contains an impartial facilitator guiding the participants through the process and a decision analyst running the DSS based on the output from the participants.

The facilitator helps to ensure that all stakeholders get an equal chance to share their knowledge and opinions, to steer the group through the process, and to explain the various techniques and model related tasks to the participants. The main tasks of the facilitator are to see and understand the group life, and to intervene, when appropriate, to help the group stay in the present and maintain a task orientation to its work. The facilitator attends to the processes occurring in the group, provide structure for the group's tasks, but refrains from contributing to content. Moreover the facilitator structures the discussions, helps participants to identify the issues and thinks creatively and imaginatively, and finally the facilitator helps the participants in how to think about the issues without suggesting what to think (Phillips 2007).

Summing up the planning workshop assists in conducting the assessment of the decision problem according to the preferences of the participants in a comprehensive and transparent way (Goodwin, Wright 2014; Phillips, Bane e Costa 2007; Phillips 2007). Following this, a structure for the workshop is developed that consists of five simple steps for the participants to consider.

\subsubsection{The five-step process}

The five-steps are formulated in order to be useful in motivating the participants to produce the input needed for the appraisal in the DSS. The steps are as depicted in Figure 3, where the arrows indicate the processes ensuring that the problem and the DSS have been completely understood and is treated thoroughly. The group work should be seen as an iterative process, and hence it is possible to go back in the process and revise the assessments made in Step 3 and 4 if shared understanding has not been achieved. The steps are described below. 


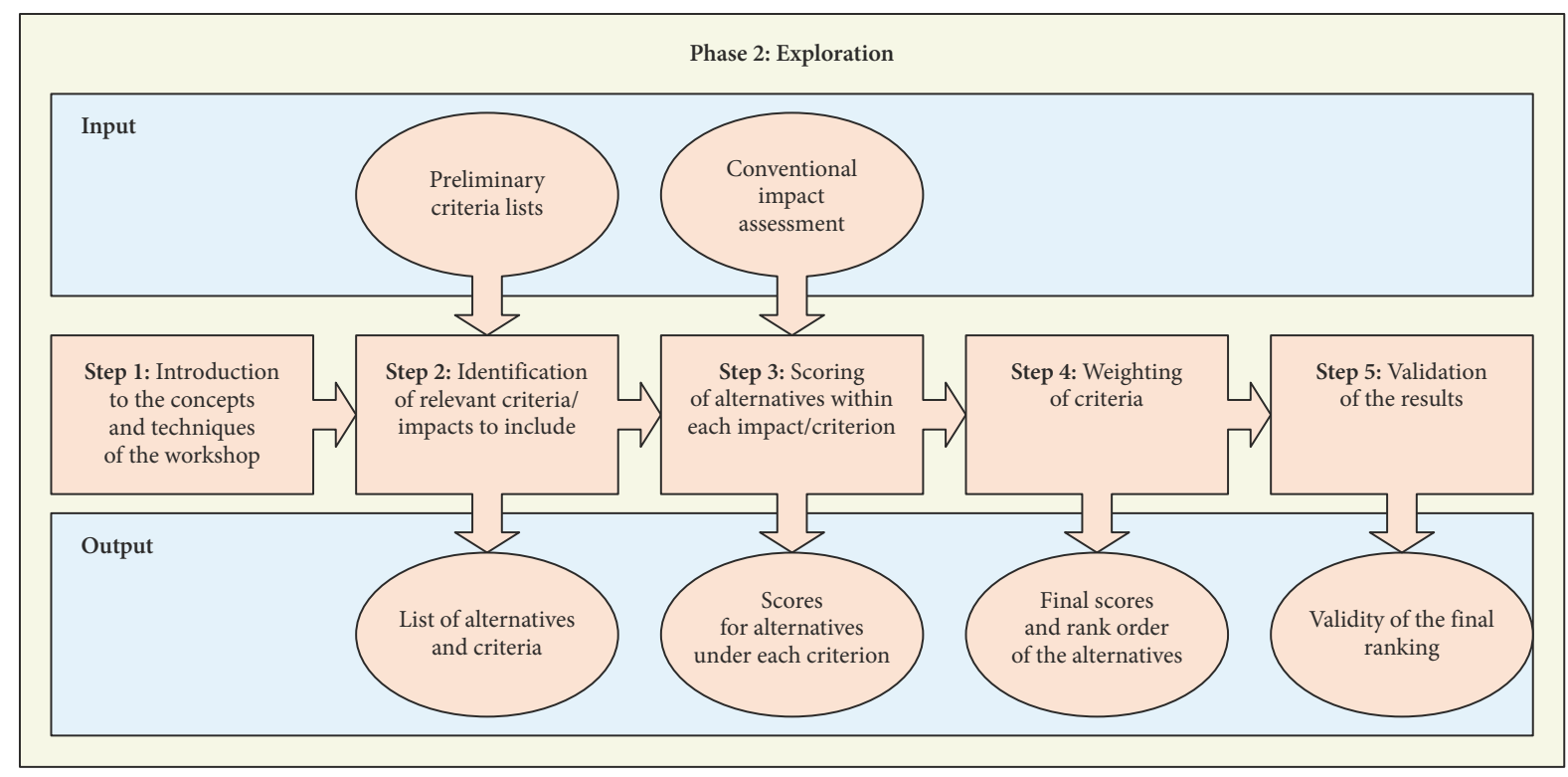

Figure 3. The exploration phase

First of all it is very important for the quality of the planning workshop that the facilitator starts by introducing the concepts and methods being used in understandable terms. If the introduction becomes too technical or theoretical some number of the participants may lose the tread, but a short practical introduction will help all participants understand how their inputs are being processed and provide a common basis on which to continue. This contributes to making the participants more comfortable with the later findings when they know the basic characteristics of the DSS. Ideally, the DSS is constructed in such an intuitive and easily accessible way that the participants do not need a thorough knowledge of the theories and techniques applied.

The Step 2 features the identification of relevant impacts for the appraisal. Such a list of criteria is already developed in the problem structuring phase (Figure 2), but the participants should have the possibility of revising the list, add more criteria, or remove irrelevant criteria if necessary. The type of criteria to include highly depends on the purpose of the workshop. If the purpose is to make an informed choice between project alternatives, the criteria to be included should contribute to the segregation of the alternatives (if all alternatives perform equally under a criterion it should be omitted from the assessment). If, on the other hand, the matter in question is whether to carry out a project initiative or not (a go/no-go decision) then the criteria to be included will often be of a more strategic economic type. The criteria list generated in the problem structuring phase might contain a lot of different criteria regardless of which of the two aforementioned appraisal tasks that are to be dealt with. Hence, it is up to the participants at the planning workshop to structure and reduce the criteria list into a number of relevant criteria for the actual decision.
Once all relevant criteria have been identified and properly defined the Step 3 comprises the scoring of the alternatives under the criteria. Dependent on the level of knowledge about the alternatives and the criteria assessed different techniques can be applied in order to elicit scores. Barfod and Salling (2015) propose the use of the following MCDA techniques for decision problems regarding transport infrastructure: the Simple Multi-Attribute Rating Technique (SMART), SMART Exploiting Ranks (SMARTER), swing weights, and the multiplicative AHP. The bullets below are based on Goodwin and Wright (2014), Belton and Stewart (2002), Lootsma (1999), Von Winterfeldt and Edwards (1986) and briefly describe the characteristics of the mentioned techniques. The reasoning behind choosing this set of techniques, which all belong to the normative approach to MCDA, is that human beings normally express their preferences in terms, which reveal gradations of intensity. As a result of this the techniques have been found appropriate to facilitate group discussions concerning transport projects (Barfod 2012b). Other types techniques such as outranking methods and fuzzy sets etc. - see e.g. Belton and Stewart (2002) - might also be useful for certain types of decision problems, and the DSS can be expanded to include such as well.

SMART. The technique is based on the additive value function model and assigns direct scores to alternatives and direct weights to criteria. The technique demands a high level of knowledge about the alternatives/criteria to be assessed and should for that reason only be used when measureable attributes can be identified for the criteria. Moreover, the technique should only be used by experienced users of decision analytic techniques.

The multiplicative AHP. The technique is a theoretical improved version of the original, additive AHP by Saaty (1977). The technique is based on making pair wise com- 
parisons of alternatives and criteria to obtain scores and weights. A nine point intensity scale of importance is used to express the preference for one object over another. The technique is simple to use as the problem is decomposed into simple judgments requiring no measurable attributes, and it is useful in situations where the alternatives are weakly described and where it is difficult to assign weights to the criteria (Barfod 2012a). The technique is useful for both experienced and non-experienced users of decision analytic techniques.

Swing weights. The techniques is usually considered to be the theoretical most correct method for deriving criteria weights, but it is most likely also the most difficult one to use in practice. The technique presupposes that the swing from worst to best performing alternative within each criterion is considered. The criteria are then ranked based on the swing that gives the highest increase in overall value. Afterwards the swings within each of the criteria are assigned with a numerical value reflecting its importance compared to the swing within the most important criterion. Finally the numerical values, e.g. percentage measures, are normalised into weights adding up to 1 . The technique should only be used by experienced users.

SMARTER. The technique is a further development of SMART. The technique is very simple in the sense that it only demands the decision-makers to rank the criteria in order of importance after which predetermined surrogate weights are assigned to the criteria. The method presupposes no measurable attributes and is easy accessible and very simple to use for non-experienced users.

Non-experienced users of decision analytic techniques users should make use of the simplest set-up as possible in order to avoid misunderstandings and misinterpretations. Thus it is recommended that the SMARTER technique is used for assigning weights to the criteria, as this only requires the users to rank the criteria in order of importance. For assigning scores to the alternatives it is recommended that the non-experienced users should make use of the multiplicative AHP, which only requires them to consider simple pair wise comparisons according to a semantic scale.

Experienced users should on the other hand be capable of perceiving more demanding methods as they often are professionals with much experience in appraisal tasks. For this reason it is recommended that the swing weight technique is applied to determine weights for the criteria, as the technique makes it possible to determine the weights with relatively high accuracy and not least with a theoretical sound interpretation. For the scoring of alternatives the SMART technique with its use of value functions is recommended for use if the attributes are measureable, if not the multiplicative AHP should be applied.

Once the techniques are selected the scoring of the alternatives begins. The participants examine the alternatives under one criterion at a time until all criteria have been thoroughly addressed. While this scoring of alternatives can be seen as being somewhat objective - as clear definitions of the criteria should reduce the groups' disagreement with regard to the alternatives' performance under the criteria - the Step 4 introduces the most subjective part of the appraisal: the weighting of the criteria.

In the Step 4 the participants are to agree upon weights for the criteria. This is considered to be a very difficult or even impossible task as very opposite world views (which may be present among the stakeholders at the planning workshop) will create very different weight sets. Instead of trying to make the participants agree, it can be useful to examine the different weight sets provided by each participant individually. These can either point out the same project alternative as being the most attractive, which of course will be the ideal result, or they can point at different project alternatives. If the latter is the case further discussion in the Step 5 might lead to a common understanding, or the decision-makers might end up with choosing their own favourite alternative. However, the decision-makers are capable of making a more informed decision after the planning workshop, as they become aware of the stakeholder groups' viewpoints and can take these into account.

The Step 5 comprises the verification and validation of the outcome of the DSS. The preceding four steps are revised to ensure that the participants still feel comfortable with the input provided. Adjustments should be made if necessary, but only if valid arguments underpin this. Hence it should not be possible to make adjustments that only try to promote a "pet" alternative. Any revisions should be recorded and documented.

\subsection{Documentation}

The final phase of the decision support process concerns the documentation of the outcome. An important aspect in this context is the recording of the judgments and choices made along the way. This is especially the case if the outcome of the workshop has to be justified to others and thorough and transparent argumentation therefore is needed. In this respect a protocol can be very useful to record the rationale of the statements made during the decision support process. If inconsistencies occur in the judgments the protocol can be helpful to clear out misunderstandings or errors, and corrections can be made effectively using the recorded rationale. Moreover, the protocol can include notes about possible disagreements in the group with regard to the judgments and how these were dealt with. A proper documentation of the planning workshop can be very helpful both with regard to the workshop itself but also when the outcome has to be justified. The protocol should therefore be seen as an integrated part of the methodology.

\section{Revising the appraisal process}

As stated in the introduction the current Danish appraisal process does not make active use of stakeholder input, which makes the appraisal somewhat narrow. However, the methodology outlined in Section 2 could with benefit 
be implemented and play a significant role in the appraisal process. The methodology can be useful both to identify the problem, to generate possible solutions, and to support the final decision making. Figure 4 depicts the proposal for how the methodology can be implemented in the Danish appraisal process.

The appraisal process starts with a need for an improvement of the infrastructure. This need (or problem) will often arise as a result of other initiatives or projects that have been carried through, or it may be due to a general increase in traffic volumes. The need may also arise as a result of a vision such as sustainable transport development. At the early stage of the appraisal process all options should open for finding an appropriate solution to the problem, and the process should be open for stakeholders to provide possible ideas for solutions. The planning workshop can in this respect be very useful to structure the process and assess the possible solutions on a set of criteria relevant for the problem. Such an initial idea generating workshop can with benefit be participated

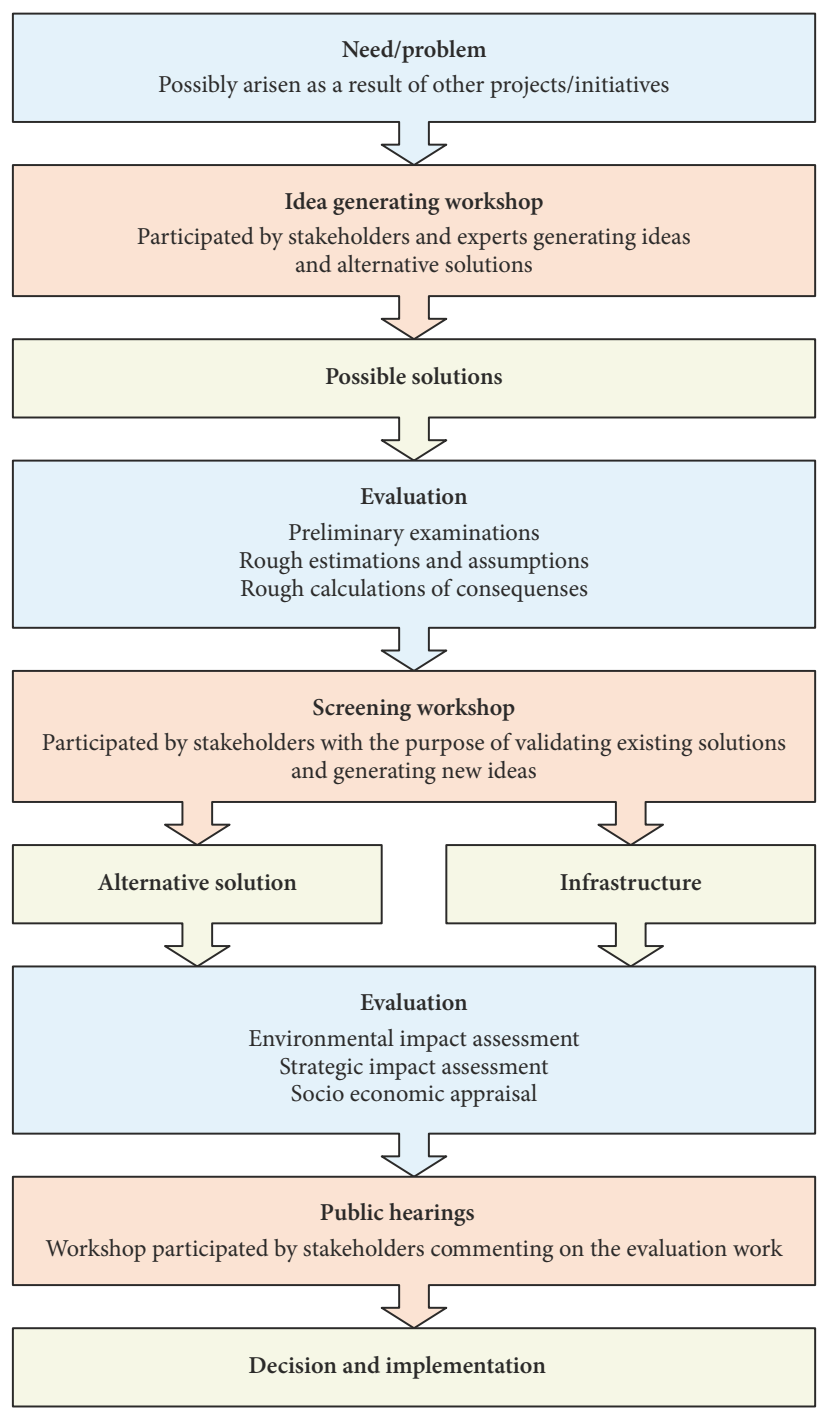

Figure 4. Implementation of the methodology in the Danish appraisal process both by stakeholders, but also by experts (e.g. from state institutions such as the road directorate and public transport operators) who have encountered similar problems before and hold valuable knowledge about possible ways of dealing with them. Bringing such a group together under the guidelines outlined in Section 2 can be expected to result in a set of alternative possible solutions. These solutions will most likely span over concrete infrastructure constructions, public transport initiatives, ITS, and other non-technical solutions.

After this preliminary evaluations of the possible solutions will be made, where some rough estimations and assumptions regarding the impacts are made. This includes preliminary CBA calculations where the main consequences such as investment costs and potential time savings are compared. The evaluations will then serve as input for the next planning workshop, which can be seen as a screening of the alternative solutions. This screening workshop is to be participated by the stakeholders who are to assess the alternative solutions with regard to both the economic viability indicated by the CBA, and the environmental and social consequences, which are handled using the MCDA techniques in the DSS. Thus alternatives can be selected or deselected from further analysis based on their performance on the economic, the social, and the environmental dimensions of sustainability. The output of the workshop is then a set of possible solutions that can either be infrastructure related or non-infrastructure related, with the latter consisting of e.g. public transport, ITS projects, or other non-technical solutions.

Finally, a socio-economic appraisal is conducted to evaluate the economic feasibility of the alternatives (DMT 2015). Using CBA the appraisal takes into account a range of monetary impacts such as travel time savings, vehicle operating costs, accidents, noise, emissions etc. Moreover an EIA is conducted to evaluate the impacts that cannot be assigned with monetary values. In the conventional appraisal process the results of these evaluations are presented at a public hearing event after which stakeholders can submit written comments on the results to the relevant institutions (e.g. the Road Directorate). Based on the results of the evaluations and the public hearing a recommendation to the political level is finally made on the 'best' solution.

Instead of basing the public hearing on written and separately treated comments from the stakeholders, the stakeholders should discuss the alternatives at a final workshop. Using the DSS it would be possible for the stakeholders to combine the results of the evaluations (the CBA and the EIA) and make recommendations to the politicians (the decision-makers). In reality it will most likely not be possible to arrive at a consensus among all the stakeholders. Instead several recommendations each reflecting the viewpoints of different stakeholder groupings can be a valuable input for the final decision-making. Political considerations will then decide what recommendation to follow. 


\section{Case study}

In order to provide an example on how the DSS makes use of the stakeholder input a case study is presented. The case concerns the decision process of improving the traffic situation across Roskilde Fjord in the northern part of Zealand, Denmark. The case description follows the three main phases of the decision support process set out in Section 2.

\subsection{The problem structuring phase}

The problem of the traffic situation across Roskilde Fjord has been an on-going debate for decades, as the current bridge connection at the city of Frederikssund has faced increasing congestion. However, due to a location within a Natura 2000 protected area, the construction of a new fixed link has been troublesome. Furthermore, the location of the existing bridge in the very city centre is restraining the possibilities for expanding the connection. An EIA has previously been conducted, and the type of solutions examined are more or less similar to those proposed when the problem was first acknowledged back in the 1960's - that is the construction of new roads and a new bridge/tunnel. No alternative solutions that are not car-oriented or based on other traffic-reducing measures have been seriously considered in the process. This is in direct conflict with the sustainability paradigm and calls for a wider set of alternatives to be considered.

In correspondence with Figure 4 an initial planning workshop was held with the purpose of generating a set of potential alternatives for solving the problem as well as defining an initial set of assessment criteria. Prior to this workshop, a stakeholder analysis was conducted to identify the participants to be included in the process. The analysis identified a broad set of stakeholders including the Ministry of Transport, the Ministry of Environment, the Road Directorate, the Transport, Construction and Housing Authority, the Region of the Greater Copenhagen Area, the municipalities of Frederikssund and Roskilde, the Bird and Wildlife Preservation Society, the Business Society of Frederikssund, and finally a citizen group named "a better connection". All stakeholders were invited to participate in the workshop with up to two representatives. All stakeholders except the Region of the Greater Copenhagen Area and Roskilde Municipality accepted the invitation.

At the workshop, a brainstorming session for possible alternatives was conducted. The participant were encouraged to think out of the box and bring all ideas to the table. This resulted in more than 20 different alternatives, which afterwards were discussed in the group. The discussions led to a reduction of the alternatives into a set that were accepted by everybody to be realistic, and the following four alternatives were brought forward to the next phase of the process. Alternatives 1 and 2 were based on the already conducted EIA, whereas Alternatives 3 and 4 were generated by the stakeholders as solutions that support a modal shift from cars to other transport modes:
- Alternative 1 (A1) is the construction of a new high level bridge south of the city centre, funded through user charge;

- Alternative 2 (A2) is an expansion of the existing bridge, also funded through user charge;

- Alternative 3 (A3) is a light rail link constructed on a new bridge close to the city centre connecting the western peninsula with the train station in Frederikssund;

- Alternative 4 (A4) is a service of free shuttle busses on the existing bridge, funded through user charge applied to other modes that use the bridge.

In the next part of the problem structuring phase the participants considered possible criteria to base the further analysis of the alternatives on. As a starting point a long list of criteria were presented to the group. This list (Figure 5) is based on background literature on the case study (Pryn 2013; Salling, Pryn 2015), as well as an interpretation of current trends in sustainable planning as described by Owens (1995) and Banister (2008). The list only served as inspiration for the group to generate their own criteria.

The participants reviewed the list and found that adjustments were needed in order to customise the list to the case study. Hence, the set of identified criteria mirror the reflections that were brought forward by the stakeholders at the workshop. The participants chose eight criteria in total, which were revised as depicted in Table 1. Thus, the set of criteria, brought forward to the exploration phase and the appraisal of the four alternatives, consisted of two economic criteria, three social criteria, and three environmental criteria. Note that as a result of the revision at the workshop the verbal designations of the criteria in Table 1 are not identical to the ones in Figure 5.

Finally, the participants agreed on the assessment techniques to apply further on in the process. As the participants were mainly non-experienced users of decision analytic techniques it was chosen to set up the DSS in its most simple mode using the SMARTER technique for assigning weights to the criteria, and using the multiplicative AHP for the assessment of the alternatives under each criterion.

\subsection{The exploration phase}

The five-step process as described in Section 2.2.1 was following applied. First, the participants were introduced to the concepts and techniques to be used in the workshop, and secondly, the criteria to base the appraisal on were identified. This step had already been conducted in the previous phase, and the participants did not feel the need to revise the criteria further. Hence, the list of criteria in Table 1 was adopted in the DSS. Note that a CBA was conducted to support the assessment of $\mathrm{C} 1$ (economic viability).

In Step 3 the participants were to assess the alternatives under each of criterion. Using the pair wise comparison technique (multiplicative AHP) all alternatives were compared to each other and assigned with a verbal preference rating. 


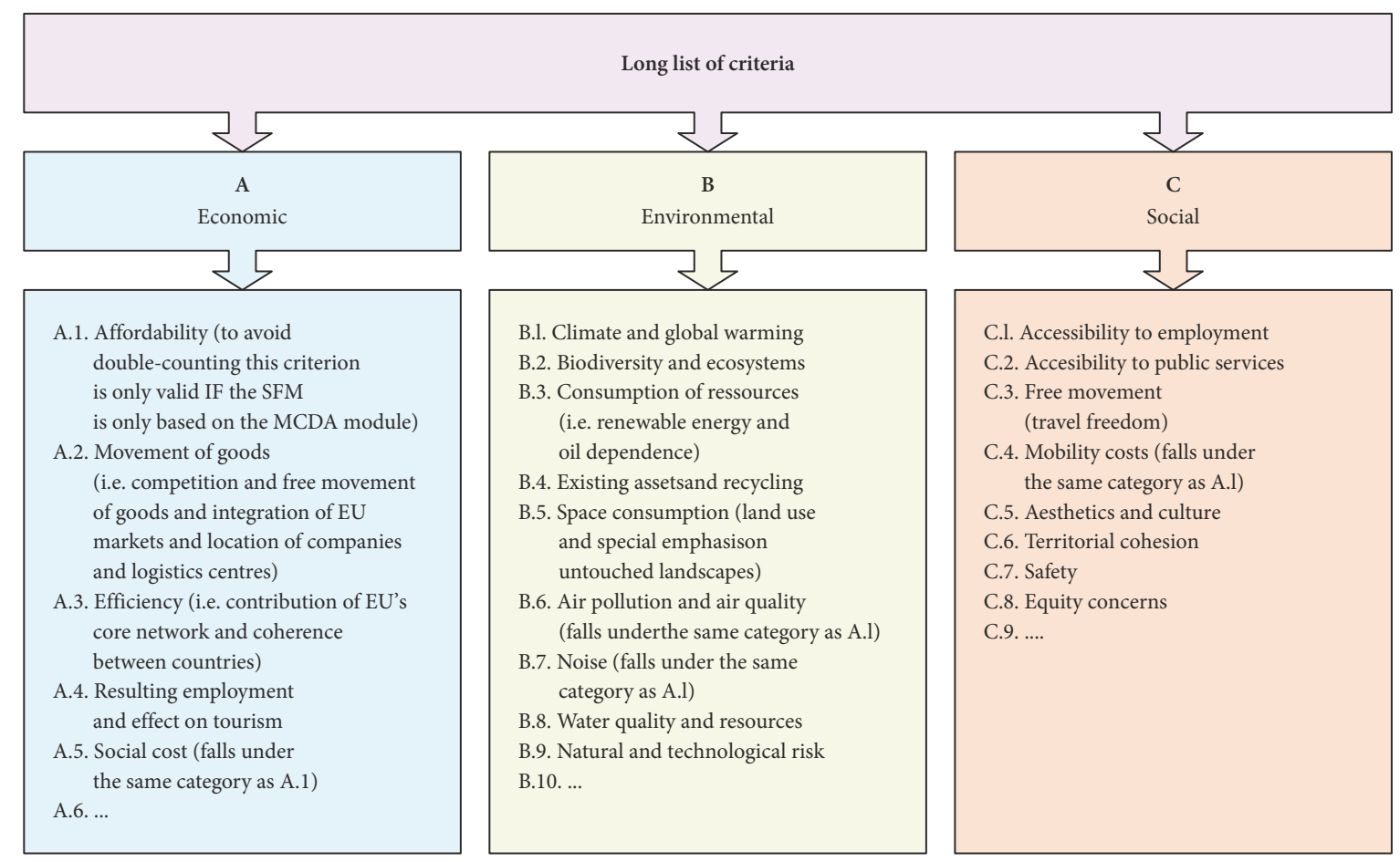

Figure 5. The long list of criteria (Salling, Pryn 2015)

Table 1. Criteria applied for the case study

\begin{tabular}{|c|c|c|}
\hline Dimension & Criteria & Definition \\
\hline \multirow[t]{2}{*}{ Economic } & C1: Economic viability & $\begin{array}{l}\text { The traditional CBA is the indicator, but is adjusted to avoid double counting } \\
\text { of the environmental effects. The criterion indicates whether the project is } \\
\text { interesting for the society economically }\end{array}$ \\
\hline & C2: Technical characteristics & $\begin{array}{l}\text { The technical requirements for the implementation of the project. Is the } \\
\text { solution based on well-known and tested technologies or does it require new } \\
\text { developments with higher associated risks etc. }\end{array}$ \\
\hline \multirow[t]{3}{*}{ Social } & $\begin{array}{l}\text { C3: Transport network } \\
\text { and accessibility }\end{array}$ & $\begin{array}{l}\text { Expected improvements in the transport network for the current users as well as } \\
\text { co-benefits for goods transportation and potential to relieve congestion }\end{array}$ \\
\hline & C4: Scenic adaption & $\begin{array}{l}\text { Contribution of the project to creating a sense of identity to the region as well as } \\
\text { adapting aesthetically to the surrounding built environment }\end{array}$ \\
\hline & $\begin{array}{l}\text { C5: Coherence between } \\
\text { regions }\end{array}$ & $\begin{array}{l}\text { Projects' contribution to create a higher coherence between surrounding regions } \\
\text { that possibly lead to increased development }\end{array}$ \\
\hline \multirow[t]{3}{*}{ Environmental } & C6: Noise & $\begin{array}{l}\text { Annoyances from noise arising from the use phase of the project. The criterion } \\
\text { does not include noise as an impact to wildlife }\end{array}$ \\
\hline & C7: Local pollution & $\begin{array}{l}\text { Perceivable local air pollution such as fine particulates and other health-related } \\
\text { emissions }\end{array}$ \\
\hline & C8: Impacts on the fjord & $\begin{array}{l}\text { Damages on nature with particular focus on the risk of irreversible damages to } \\
\text { the local fiord ecosystem. This includes impacts on water flow, bird life, wildlife, } \\
\text { the marine environment, underground water, soil etc. }\end{array}$ \\
\hline
\end{tabular}

In the technique the verbal information from the pair wise comparisons are converted into numerical values according to the intensity scale going from 0 (indifference) to 8 (very strong difference) and filled into the comparison matrices of the DSS. An example of such a matrix is shown in Table 2 depicting the results of the assessment of alternatives under the 'local pollution' criterion. For more information about the calculations using the multiplicative AHP see e.g. Olson et al. (1995).
Table 2. Comparison matrix for the local pollution criterion

\begin{tabular}{|c|c|c|c|c|c|}
\hline $\begin{array}{c}\text { Criteria 7: } \\
\text { local pollution }\end{array}$ & A1 & A2 & A3 & A4 & Calculated score \\
\hline A1 & 0 & -2 & -4 & -6 & 0.13 \\
\hline A2 & 2 & 0 & -3 & -4 & 0.42 \\
\hline A3 & 4 & 3 & 0 & -2 & 2.38 \\
\hline A4 & 6 & 4 & 2 & 0 & 8.00 \\
\hline
\end{tabular}


Table 3. Scores and weights from the assessment process

\begin{tabular}{|c|c|c|c|c|c|c|c|c|c|}
\cline { 2 - 10 } \multicolumn{1}{c|}{} & $\mathrm{C} 1$ & $\mathrm{C} 2$ & $\mathrm{C} 3$ & $\mathrm{C} 4$ & $\mathrm{C} 5$ & $\mathrm{C} 6$ & $\mathrm{C} 7$ & C8 & Total score \\
\hline Weight & $(0.0531)$ & $(0.0263)$ & $(0.1672)$ & $(0.1977)$ & $(0.0805)$ & $(0.1084)$ & $(0.2292)$ & $(0.1375)$ & 0.21 \\
\hline A1 & 16.00 & 9.51 & 9.51 & 6.73 & 8.00 & 0.30 & 0.13 & 0.32 \\
\hline A2 & 1.68 & 1.68 & 1.68 & 0.35 & 0.60 & 0.30 & 0.42 & 1.68 & 0.16 \\
\hline A3 & 0.04 & 0.09 & 0.60 & 0.35 & 1.68 & 2.38 & 2.38 & 0.60 & 0.18 \\
\hline A4 & 0.84 & 0.71 & 0.11 & 1.19 & 0.13 & 4.76 & 8.00 & 4.76 & 0.33 \\
\hline
\end{tabular}

After the scoring process the criteria weights were determined in Step 4. Using the SMARTER technique the group was asked to rank the criteria in order of importance. This ranking was first done individually by each group member, and afterwards the group made an attempt to set up a ranking reflecting a compromised common agreement. In this way both a compromised solution could be presented as well as solutions reflecting each participant's viewpoint. According to the SMARTER technique the criteria were then assigned with Rank Order Distribution (ROD) weights, which are pre-determined surrogate weights expressing a close approximation to real weights (Roberts, Goodwin 2002).

The weights, depicted in Table 3 along with the scores of the alternatives under the criteria, reflect the participants' common recommendation that prioritises sustainability viewpoints, i.e. giving higher importance and accordingly higher weights to the criteria involving "green" aspects. In Table 3 the contributions from each criterion are summarised into total scores using a multiplicative aggregation.

In Step 5 the previous steps were validated by revising the judgments made along the process. This only led to some minor corrections, which were recorded in the protocol. Finally the results were presented to the participants.

Alternative 1 (a new bridge) clearly performs best within the economic criteria ( $\mathrm{C} 1$ and $\mathrm{C} 2)$, but the results reveal that Alternative 4 (free shuttle busses) performs best when great considerations are made on the "green" (environmental) aspects. Alternative 4 performs much better than Alternative 1 on the environmental criteria, and even though the economic performance is not very good it can be viewed as an overall more sustainable alternative. However, the difference in total scores for Alternatives 1 and 4 ( 0.32 and 0.33 respectively) is so low that in practice it is not possible to state that one is better than the other. Instead, the result implies that further analysis is necessary before a final recommendation can be made.

\subsection{The documentation phase}

The process was documented through all the phases in order to produce a defendable rationale. In this way it is possible for people not being present at the workshop to review the process, arguments for choices etc. At this specific occasion it was actually possible for the stakeholders to agree upon a weighting of the criteria. Moreover, the criteria chosen for this case may seem rather conservative with regard to sustainability appraisals, and they more or less reflect the criteria that are used in the EIA today. It could easily be imagined that another group of stakeholders would focus more on criteria of an environmental and social character in their appraisal of the issue, and the result will naturally reflect this. As mentioned in Section 3 it is most likely that not all stakeholder groupings will agree on what criteria to include in the assessment and how they should be weighted. Therefore planning workshops can be held separately for stakeholder groupings, and each of them can provide the decision-makers with a recommendation that reflects their view on the issue. It is then up to the decision-makers to use the decision support in the best possible way.

As a final part of the workshop the participants were asked to evaluate the methodology and its perspectives for inclusion in the Danish appraisal process. Overall, the participants were very satisfied with the process, and indicated that it had been an "eye opener" to other solutions than what their organisations normally promoted. Even though not all were convinced that the methodology should be a permanent part of the appraisal process, all agreed that it was nice to get a different perspective on the issue at hand.

\section{Discussion}

This paper has made a proposal for bridging the gap between the conventional CBA based approach to transport project appraisal and the assessments of non-monetary impacts by using stakeholder involvement and MCDA, and has enhanced and combined main findings from previous research in a novel approach to support sustainable transport planning. A focus of the paper has been to propose an approach that can be implemented in the current Danish transport appraisal scheme, and for this reason, a case study has been examined using the approach.

The proposed methodology consists of three main phases of the decision support process to be implemented in the Danish transport appraisal scheme mainly featuring the use of planning workshops. This concept is effective to include in the appraisal process for transport projects for several reasons. First, if the participants are selected to represent all key perspectives on the issues, agreed actions are unlikely to be stopped by someone else arguing 
that the group failed to consider a major factor. Second, the participants become aware of the real issues, which help the group to build consensus about the way forward. Third, the approach plays a crucial role in generating commitment meaning that the participants generate all inputs to the DSS and nothing is imposed. Thereby the final model is the creation of the group, and 'owned' by the participants. Perhaps most important, the DSS helps to minimise the threat from particular concerns present in the group processes: the DSS reveals higher-level perspectives that can resolve differences in individual views, and shows agreement about the way forward in spite of differences of opinion about details. The DSS allows the participants to try different judgments without commitment, to see the results, and then to change their views. However, customising a DSS to fit the specific assessment task in hand places high demands on the decision analysts to identify and use the most appropriate MCDA techniques. There is no such thing as "the overall best technique", so for each single issue it is necessary to make a thorough assessment of which technique (or techniques) that is most appropriate to use. Section 2 presented a selection of four techniques that by previous studies have proven appropriate to use when dealing with transport projects. However, the DSS is not limited to these techniques. Depending on the nature of the decision problem at hand, other techniques might be more appropriate to use, and if so, these can be implemented in the methodology with ease.

The concept of planning workshops has provided an approach that can be implemented in the Danish transport appraisal process and in countries with similar current approaches. The outlined concept making use of well-established methods enables a structured debate between owners of the problem, decision-makers, experts and various groups of affected stakeholders. This is an important task, which is often requested in situations where infrastructure projects are to be assessed. Furthermore it is relevant in relation to the operationalization of the social and environmental dimension of the concept of sustainability within the transport appraisal process. Still there is a need to combine planning workshops with other methodologies than CBA and MCDA in order to operationalise all three dimensions of sustainability within the appraisal scheme. Specifically, methods or techniques that help to understand the problem situation, so the planning workshop can have the right content and target are essential points. An initial attempt to this have been made with the proposed problem structuring phase (Section 2.1). However, this needs be further developed. Other complications regarding the use of planning workshops for transport appraisal is the time and the resource demand, which need to be resolved.

Recommendations made in consensus at a planning workshop seem to have a fairly higher probability for being implemented compared to results from a complex decision analysis that only involves one decision-maker who later has to justify their decision for other people.
Moreover, decisions made by such groups have better terms for working in practice as they have the group's commitment. However, there is one large question that has to be answered: Are recommendations made in consensus at a planning workshop using a DSS more or less valid and sustainable than assessments and solutions made without these aids? According to Phillips (2007) this is not necessarily the case, however, it is evident that a planning workshop provides some advantages regarding: better communication between groups, a common understanding of strategic objectives and hence common commitment towards the objective, improved teamwork, better knowledge and relation to various uncertainties, and finally and foremost decisions that can be defended. One way of measuring the success of a planning workshop is as facilitator to see whether the workshop has transformed the participants from being uninformed and detached as regards the complex planning problem into being informed and involved in a common final agreement (Leleur 2012).

\section{Conclusions}

This paper has proposed a methodology consisting of three main phases that involve stakeholders in the decision support process for transport infrastructure initiatives applying the concept of a planning workshop. In order to participate meaningfully in the process and to make well-informed decisions, the decision-makers are in need of information from decision techniques that can assist in assessing the implications of project initiatives. This paper has examined how available data and decision analytic techniques can be used for group decision support dealing with the three interrelated domains of sustainability: economy, environment and society. The decision support process that has been set out is divided into the three main phases of problem structuring, exploration and documentation that are to be dealt with.

Thus the planning workshop has been set out to be a component in the Danish planning process that in an easily accessible and transparent manner can lead the participants through the appraisal task. The DSS consisting of different MCDA techniques is applied to support the appraisal process thereby obtaining a more comprehensive appraisal featuring all relevant impacts.

The proposed DSS in combination with a planning workshop is concluded to be an effective decision support aid when complex decisions regarding transport infrastructure have to be made. The proposed methodology provides a customised process, which seeks to give all stakeholders an opportunity to express their preferences and influence the outcome of the appraisal. Hence, the methodology makes it possible for the decision-makers to make informed decisions that include considerations with regard to all three dimensions of sustainability. The methodology does not ensure that the final chosen project is sustainable, but if the criteria are carefully selected it does ensure that the most sustainable of the projects under consideration is chosen. 
It has been demonstrated how the methodology including the concept of the planning workshop in combination with the DSS can be implemented in the current Danish appraisal process and then also in countries with similar current approaches. On this background, the methodology is concluded to be worthwhile and useful both in the problem structuring phase where the problem becomes known and possible solutions emerge, in the exploration phase where the solutions become concrete, and in the documentation phase where the process is validated and a final decision made. The case study furthermore reveals that a change in perspective away from the strong focus on economy promoting conventional projects can result in more environmental friendly and social wellfounded solutions to transport problems.

\section{Disclosure statement}

The research presented in this paper is not affected by any competing financial, professional, or personal interests from other parties.

\section{References}

Abelson, J.; Forset, P.-G.; Eyles, J.; Casebeer, A.; Martin, E.; Mackean, G. 2007. Examining the role of context in the implementation of a deliberative public participation experiment: results from a Canadian comparative study, Social Science \& Medicine 64(10): 2115-2128.

https://doi.org/10.1016/j.socscimed.2007.01.013

Awasthi, A.; Chauhan, S. S. 2011. Using AHP and DempsterShafer theory for evaluating sustainable transport solutions, Environmental Modelling \& Software 26(6): 787-796.

https://doi.org/10.1016/j.envsoft.2010.11.010

Awasthi, A.; Chauhan, S. S.; Omrani, H. 2011. Application of fuzzy TOPSIS in evaluating sustainable transportation systems, Expert Systems with Applications 38(10): 12270-12280. https://doi.org/10.1016/j.eswa.2011.04.005

Bana e Costa, C. A. 2001. The use of multi-criteria decision analysis to support the search for less conflicting policy options in a multi-actor context: case study, Journal of Multi-Criteria Decision Analysis 10(2): 111-125.

https://doi.org/10.1002/mcda.292

Banister, D. 2008. The sustainable mobility paradigm, Transport Policy 15(2): 73-80.

https://doi.org/10.1016/j.tranpol.2007.10.005

Barfod, M. B. 2012a. An MCDA approach for the selection of bike projects based on structuring and appraising activities, European Journal of Operational Research 218(3): 810-818. https://doi.org/10.1016/j.ejor.2011.11.038

Barfod, M. B. 2012b. Optimising Transport Decision Making Using Customised Decision Models and Decision Conferences: PhD Thesis. Technical University of Denmark. 193 p. Available from Internet: http://orbit.dtu.dk/files/52281928/mbb_ thesis.pdf

Barfod, M. B.; Salling, K. B. 2015. A new composite decision support framework for strategic and sustainable transport appraisals, Transportation Research Part A: Policy and Practice 72: 1-15. https://doi.org/10.1016/j.tra.2014.12.001
Belton, V.; Stewart, T. 2002. Multiple Criteria Decision Analysis: an Integrated Approach. Springer. $372 \mathrm{p}$.

https://doi.org/10.1007/978-1-4615-1495-4

Beukers, E.; Bertolini, L.; Te Brömmelstroet, M. 2012. Why Cost Benefit Analysis is perceived as a problematic tool for assessment of transport plans: a process perspective, Transportation Research Part A: Policy and Practice 46(1): 68-78. https://doi.org/10.1016/j.tra.2011.09.004

Camargo Pérez, J.; Carrillo, M. H.; Montoya-Torres, J. R. 2015. Multi-criteria approaches for urban passenger transport systems: a literature review, Annals of Operations Research 226(1): 69-87. https://doi.org/10.1007/s10479-014-1681-8

Checkland, P. 1999. Systems Thinking, Systems Practice: Includes a 30-Year Retrospective. Wiley. $424 \mathrm{p}$.

Damart, S.; Roy, B. 2009. The uses of cost-benefit analysis in public transportation decision-making in France, Transport Policy 16(4): 200-212.

https://doi.org/10.1016/j.tranpol.2009.06.002

Davidson, S. 1998. Spinning the wheel of empowerment, Planning (4): 14-15.

DMT. 2015. Manual for Socio-Economic Appraisal within the Transport Sector. Danish Ministry of Transport (DMT), Copenhagen, Denmark.

Ewing, G.; Sarigöllü, E. 2000. Assessing consumer preferences for clean-fuel vehicles: a discrete choice experiment, Journal of Public Policy \& Marketing 19(1): 106-118. https://doi.org/10.1509/jppm.19.1.106.16946

Fedra, K. 2004. Sustainable urban transportation: a model-based approach, Cybernetics and Systems: an International Journal 35(5-6): 455-485. https://doi.org/10.1080/01969720490451779

Franceschini, S.; Marletto, G. 2015. Assessing the benefits and the shortcomings of participation - findings from a test in Bari (Italy), Journal of Transport Geography 44: 33-42. https://doi.org/10.1016/j.jtrangeo.2015.02.008

Goodwin, P.; Wright, G. 2014. Decision Analysis for Management Judgment. Wiley. 496 p.

Grimble, R.; Wellard, K. 1997. Stakeholder methodologies in natural resource management: a review of principles, contexts, experiences and opportunities, Agricultural Systems 55(2): 173-193. https://doi.org/10.1016/S0308-521X(97)00006-1

Hansen, H. S.; Mäenpää, M. 2008. An overview of the challenges for public participation in river basin management and planning, Management of Environmental Quality: an International Journal 19(1): 67-84.

https://doi.org/10.1108/14777830810840372

Hayashi, Y.; Morisugi, H. 2000. International comparison of background concept and methodology of transportation project appraisal, Transport Policy 7(1): 73-88. https://doi.org/10.1016/S0967-070X(00)00015-9

Hsu, C.-Y.; Yang, C.-S.; Yu, L.-C.; Lin, C.-F.; Yao, H.-H.; Chen, D.-Y.; Lai, K. R.; Chang, P.-C. 2015. Development of a cloud-based service framework for energy conservation in a sustainable intelligent transportation system, International Journal of Production Economics 164: 454-461. https://doi.org/10.1016/j.ijpe.2014.08.014

Jeon, C. M.; Amekudzi, A. 2005. Addressing sustainability in transportation systems: definitions, indicators, and metrics, Journal of Infrastructure Systems 11(1): 31-50. https://doi.org/10.1061/(ASCE)1076-0342(2005)11:1(31)

Jeppesen, S. L. 2009. Sustainable Transport Planning - A MultiMethodology Approach to Decision Making: PhD Thesis. Tech- 
nical University of Denmark. 213 p. Available from Internet: http://orbit.dtu.dk/files/5138927/PhDthesis-SaraLiseJeppesen.pdf

Jones, S.; Tefe, M.; Appiah-Opoku, S. 2015. Incorporating stakeholder input into transport project selection - a step towards urban prosperity in developing countries?, Habitat International 45(1): 20-28.

https://doi.org/10.1016/j.habitatint.2014.06.017

Karjalainen, T. P.; Rossi, P. M.; Ala-Aho, P.; Eskelinen, R.; Reinikainen, K.; Kløve, B.; Pulido-Velazquez, M.; Yang, H. 2013. A decision analysis framework for stakeholder involvement and learning in groundwater management, Hydrology and Earth System Sciences: an Interactive Open-Access Journal of the European Geosciences Union 17(12): 5141-5153.

https://doi.org/10.5194/hess-17-5141-2013

Keshkamat, S. S.; Looijen, J. M.; Zuidgeest, M. H. P. 2009. The formulation and evaluation of transport route planning alternatives: a spatial decision support system for the Via Baltica project, Poland, Journal of Transport Geography 17(1): 54-64. https://doi.org/10.1016/j.jtrangeo.2008.04.010

Kropp, W. W.; Lein, J. K. 2012. Assessing the geographic expression of urban sustainability: a scenario based approach incorporating spatial multicriteria decision analysis, Sustainability 4(9): 2348-2365. https://doi.org/10.3390/su4092348

Leleur, S. 2012. Complex Strategic Choices: Applying Systemic Planning for Strategic Decision Making. Springer. $170 \mathrm{p}$. https://doi.org/10.1007/978-1-4471-2491-7

Leleur, S. 2000. Road Infrastructure Planning: a Decision-Oriented Approach. Polytekisk Forlag. 256 p.

Lootsma, F. A. 1999. Multi-Criteria Decision Analysis via Ratio and Difference Judgement. Springer. $286 \mathrm{p}$.

https://doi.org/10.1007/b102374

López, E.; Monzón, A.; Pfaffenbichler, P. C. 2012. Assessment of energy efficiency and sustainability scenarios in the transport system, European Transport Research Review 4(1): 47-56. https://doi.org/10.1007/s12544-011-0063-4

Luyet, V.; Schlaepfer, R.; Parlange, M. B.; Buttler, A. 2012. A framework to implement stakeholder participation in environmental projects, Journal of Environmental Management 111: 213-219. https://doi.org/10.1016/j.jenvman.2012.06.026

Macharis, C.; Turcksin, L.; Lebeau, K. 2012. Multi actor multi criteria analysis (MAMCA) as a tool to support sustainable decisions: state of use, Decision Support Systems 54(1): 610620. https://doi.org/10.1016/j.dss.2012.08.008

Malczewski, J. 1996. A GIS-based approach to multiple criteria group decision-making, International Journal of Geographical Information Systems 10(8): 955-971.

https://doi.org/10.1080/02693799608902119

Malczewski, J. 2006. GIS-based multicriteria decision analysis: a survey of the literature, International Journal of Geographical Information Science 20(7): 703-726.

https://doi.org/10.1080/13658810600661508

Mardani, A.; Zavadskas, E. K.; Khalifah, Z.; Jusoh, A.; Nor, K. 2016. Multiple criteria decision-making techniques in transportation systems: a systematic review of the state of the art literature, Transport 31(3): 359-385.

https://doi.org/10.3846/16484142.2015.1121517

Mohamadabadi, H. S.; Tichkowsky, G.; Kumar, A. 2009. Development of a multi-criteria assessment model for ranking of renewable and non-renewable transportation fuel vehicles, Energy 34(1): 112-125.

https://doi.org/10.1016/j.energy.2008.09.004
Noland, R. B. 2007. Transport planning and environmental assessment: implications of induced travel effects, International Journal of Sustainable Transportation 1(1): 1-28.

https://doi.org/10.1080/15568310601095131

OECD. 2001. Citizens as Partners: Information, Consultation and Public Participation in Policy-Making. Organisation for Economic Cooperation and Development (OECD) Publishing. 268 p. https://doi.org/10.1787/9789264195561-en

Olson, D. L.; Fliedner, G.; Currie, K. 1995. Comparison of the REMBRANDT system with analytic hierarchy process, European Journal of Operational Research 82(3): 522-539. https://doi.org/10.1016/0377-2217(93)E0340-4

Owens, S. 1995. From 'predict and provide' to 'predict and prevent'?: pricing and planning in transport policy, Transport Policy 2(1): 43-49. https://doi.org/10.1016/0967-070X(95)93245-T

Pai, T.-Y.; Hanaki, K.; Ho, H.-H.; Hsieh, C.-M. 2007. Using grey system theory to evaluate transportation effects on air quality trends in Japan, Transportation Research Part D: Transport and Environment 12(3): 158-166.

https://doi.org/10.1016/j.trd.2007.01.007

Phillips, L. D. 1984. A theory of requisite decision models, Acta Psychologica 56(1-3): 29-48.

https://doi.org/10.1016/0001-6918(84)90005-2

Phillips, L. D. 2007. Decision conferencing, in: W. Edwards, R. F. Miles, D. von Winterfeldt (Eds.). Advances in Decision Analysis: from Foundations to Applications, 375-399. https://doi.org/10.1017/CBO9780511611308.020

Phillips, L. D.; Bane e Costa, C. A. 2007. Transparent prioritisation, budgeting and resource allocation with multi-criteria decision analysis and decision conferencing, Annals of Operations Research 154(1): 51-68. https://doi.org/10.1007/s10479-007-0183-3

Pryn, M. R. 2013. Sustainable Decision Support - a Contextual Analysis of the Importance of Planning Criteria Using MCDA. Technical University of Denmark.

Pryn, M. R.; Cornet, Y.; Salling, K. B. 2015. Applying sustainability theory to transport infrastructure assessment using a multiplicative AHP decision support model, Transport 30(3): 330-341. https://doi.org/10.3846/16484142.2015.1081281

Reed, M. S. 2008. Stakeholder participation for environmental management: a literature review, Biological Conservation 141(10): 2417-2431. https://doi.org/10.1016/j.biocon.2008.07.014

Roberts, R.; Goodwin, P. 2002. Weight approximations in multiattribute decision models, Journal of Multi-Criteria Decision Analysis: Optimization, Learning, and Decision Support 11(6): 291-303. https://doi.org/10.1002/mcda.320

Saaty, T. L. 1977. Scenarios and priorities in transport planning: application to the Sudan, Transportation Research 11(5): 343350. https://doi.org/10.1016/0041-1647(77)90044-2

Salling, K. B.; Pryn, M. R. 2015. Sustainable transport project evaluation and decision support: indicators and planning criteria for sustainable development, International Journal of Sustainable Development \& World Ecology 22(4): 346-357. https://doi.org/10.1080/13504509.2015.1051497

Sayers, T. M.; Jessop, A. T.; Hills, P. J. 2003. Multi-criteria evaluation of transport options - flexible, transparent and userfriendly?, Transport Policy 10(2): 95-105. https://doi.org/10.1016/S0967-070X(02)00049-5

Shiau, T.-A. 2012. Evaluating sustainable transport strategies with incomplete information for Taipei City, Transportation Research Part D: Transport and Environment 17(6): 427-432. https://doi.org/10.1016/j.trd.2012.05.002 
Shiau, T.-A.; Liu, J.-S. 2013. Developing an indicator system for local governments to evaluate transport sustainability strategies, Ecological Indicators 34: 361-371. https://doi.org/10.1016/j.ecolind.2013.06.001

Shiftan, Y.; Kaplan, S.; Hakkert, S. 2003. Scenario building as a tool for planning a sustainable transportation system, Transportation Research Part D: Transport and Environment 8(5): 323-342. https://doi.org/10.1016/S1361-9209(03)00020-8

Steelman, T. A.; Ascher, W. 1997. Public involvement methods in natural resource policy making: advantages, disadvantages and trade-offs, Policy Sciences 30: 71-90. https://doi.org/10.2139/ssrn.1931047

Stich, B.; Holland, J. H. 2011. Using a multiple criteria decisionmaking model to streamline and enhance nepa and public participation processes, Public Works Management \& Policy 16(1): 59-89. https://doi.org/10.1177/1087724X10390227

Tzeng, G.-H.; Lin, C.-W.; Opricovic, S. 2005. Multi-criteria analysis of alternative-fuel buses for public transportation, Energy Policy 33(11): 1373-1383.

https://doi.org/10.1016/j.enpol.2003.12.014

Vickerman, R. 2000. Evaluation methodologies for transport projects in the United Kingdom, Transport Policy 7(1): 7-16. https://doi.org/10.1016/S0967-070X(00)00009-3

Von Winterfeldt, D.; Edwards, W. 1986. Decision Analysis and Behavioral Research. Cambridge University Press. 624 p.

World Bank. 1996. The World Bank Participation Sourcebook. The World Bank, Washington, DC, US. 280 p.

Yedla, S.; Shrestha, R. M. 2003. Multi-criteria approach for the selection of alternative options for environmentally sustainable transport system in Delhi, Transportation Research Part A: Policy and Practice 37(8): 717-729.

https://doi.org/10.1016/S0965-8564(03)00027-2 